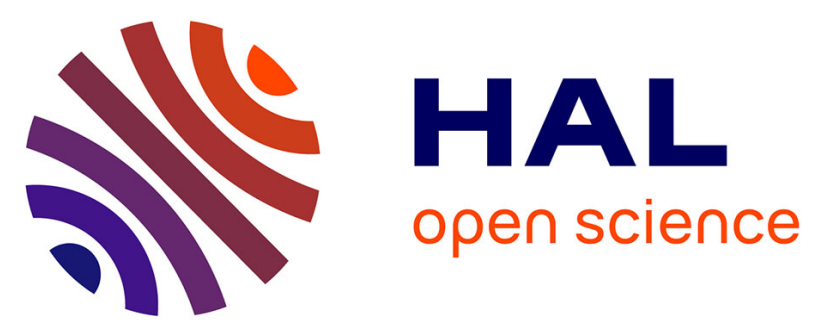

\title{
$\beta$-Cyclodextrin PAMAM Dendrimer: How to Overcome the Tumbling Process for Getting Fully Available Host Cavities
}

Israel González-Méndez, Aurélien Hameau, Regis Laurent, Christian Bijani, Valérie Bourdon, Anne-Marie Caminade, Ernesto Rivera, Kathleen Moineau-Chane Ching

\section{To cite this version:}

Israel González-Méndez, Aurélien Hameau, Regis Laurent, Christian Bijani, Valérie Bourdon, et al.. $\beta$-Cyclodextrin PAMAM Dendrimer: How to Overcome the Tumbling Process for Getting Fully Available Host Cavities. European Journal of Organic Chemistry, 2020, 2020 (9), pp.1114-1121. 10.1002/ejoc.201901823 . hal-02501116

\section{HAL Id: hal-02501116 \\ https://hal.science/hal-02501116}

Submitted on 23 Oct 2020

HAL is a multi-disciplinary open access archive for the deposit and dissemination of scientific research documents, whether they are published or not. The documents may come from teaching and research institutions in France or abroad, or from public or private research centers.
L'archive ouverte pluridisciplinaire HAL, est destinée au dépôt et à la diffusion de documents scientifiques de niveau recherche, publiés ou non, émanant des établissements d'enseignement et de recherche français ou étrangers, des laboratoires publics ou privés. 


\title{
$\beta$-Cyclodextrin PAMAM dendrimer: how to overcome the tumbling process for getting fully available host cavities
}

\author{
Israel González-Méndez, ${ }^{[a]}$ Aurélien Hameau, ${ }^{[b, c]}$ Régis Laurent, ${ }^{[b, c]}$ Christian Bijani, ${ }^{[b, c]}$ Valérie \\ Bourdon, ${ }^{[\mathrm{d}]}$ Anne-Marie Caminade, ${ }^{[\mathrm{b}, \mathrm{c}]}$ Ernesto Rivera, ${ }^{[\mathrm{a}] *}$ and Kathleen I. Moineau-Chane Ching ${ }^{[\mathrm{b}, \mathrm{c}] *}$
}

[a] Instituto de Investigaciones en Materiales, Universidad Nacional Autónoma de México, Circuito Exterior Ciudad Universitaria C.P. 04510, Ciudad de México, México.

E-mail : riverage@unam.mx ; http://www.iim.unam.mx/erivera/

[b] CNRS; LCC (Laboratoire de Chimie de Coordination); 205 route de Narbonne, BP 44099, F-31077 Toulouse, Cedex 4, France

E-mail : kathleen.chane@lcc-toulouse.fr ; https://www.lcc-toulouse.fr/auteur744.html

[c] LCC-CNRS, Université de Toulouse, CNRS, Toulouse, France

[d] ICT - Service de spectrométrie de masse - Université Paul Sabatier, 118, Route de Narbonne, 31062 Toulouse Cedex 9 , France

Supporting information for this article is given via a link at the end of the document.

Keywords: $\beta$-cyclodextrin $•$ Click Chemistry $・$ PAMAM $・$ dendrimer $\bullet$ tumbling process

\begin{abstract}
The synthesis of a G0 polyamidoamide (PAMAM) dendrimer end-capped with four $\beta$-cyclodextrin $(\beta-C D)$ units, named as Tetra-CD was performed by using copper(l)-catalyzed alkyneazide cycloaddition (CuAAC). This new platform presents a considerable high water-solubility in comparison to native $\beta-C D$. Tumbling process involving half of the $C D$ cavities in $D_{2} \mathrm{O}$ was evidenced by ${ }^{1} \mathrm{H}$ NMR spectroscopy. Interaction of adamantane with Tetra-CD has been fully investigated by 1D/2D NMR techniques and mass spectrometry besides a joint study on new $\beta-C D$ monomers (named as $\mathbf{A}$ and $\mathbf{B}$ ) and on a dimer (Di-CD) and a trimer (Tri-CD). The obtained results demonstrate that the tumbling effect can be shifted in the presence of an appropriate hydrophobic guest resulting in the full host-ability of the CD units in water for that guest.
\end{abstract}

\section{Introduction}

Cyclodextrins (CDs) are a series of natural cyclic oligosaccharides comprising 6, 7 or $8 \mathrm{D}-(+)$-glucopyranose units linked by $\alpha-1,4$-linkages, named as $\alpha-, \beta$ - or $\gamma-C D$, respectively, ${ }^{[1]}$ represented as a truncated cones with a hydrophilic exterior and a hydrophobic inner cavity. Their water-solubility is not correlated with their size but with the ability of their hydroxyl groups to form hydrogen bonds with water. It can be improved by eventual chemical modifications on these $\mathrm{OH}$ groups situated on the edges of the conical cylinder. Thanks to its size, hydrophobicity and hydrogen bonding of its inner cavity, $\beta-C D$ can accommodate diverse guest molecules. Its low cost, water-solubility and biocompatible properties ${ }^{[2]}$ make it a molecule of choice for the construction of supramolecular systems. ${ }^{[3]}$ The interaction of CD with non-water-soluble molecules operates via a dynamic equilibrium process of host-guest complexation, following which the guest molecules continuously associate and dissociate from the CD cavity. Due to its inner cavity diameter of around $6.5 \AA$, $\beta-C D$ has been found to be particularly attractive for preparation of drugs delivery systems. ${ }^{[4]}$

Chemical modification of native $\beta$-CDs have been performed via reactions on the primary or secondary hydroxyl groups ${ }^{[5]}$ leading to decorated $\beta-C D s$, formation of $\beta-C D$ polymers, ${ }^{[6]}$ or generation of $C D$ nanosponges. ${ }^{[7]}$ Among the used synthetic techniques, the copper(I)-catalysed alkyne-azide cycloaddition (CuAAC) "click" reaction ${ }^{[8]}$ has emerged as one of the most valuable synthetic tools in the development of a wide variety of $C D$ derivatives for biological applications in various fields, due to its simplicity, efficiency, and robustness properties. ${ }^{[9]}$ CuAAC is used for cycloaddition of the mono azido cyclodextrin ( $\left.\boldsymbol{\beta}-\mathbf{C D}-\mathbf{N}_{3}\right)$, obtained from the mono-(O-6)-tosylated $\beta-C D,{ }^{[10]}$ on the appropriate alkyne. ${ }^{[11]}$ In that way, a hydrophobic moiety can be grafted on one primary hydroxyl function of $\beta-C D$ for obtaining $C D$ monomers ${ }^{[12]}$ or more complex assemblies ${ }^{[13]}$ with modulated inclusion and transport properties. Besides, the use of hydrophilic dendritic structures has been proved to be a suitable strategy for obtaining highly soluble active ingredients in water. ${ }^{[14]}$

In the present work, we used this strategy for designing a new platform, named as Tetra-CD, based on a central G0 PAMAM dendrimer (IV) substituted by $4 \beta-C D$ units via spacers formed by CuAAC. The presence of 4 peripheral $\beta-C D$ units confers to this compound a high potential of guest accommodation. The PAMAM core was chosen because it could contribute to great solubility in water for Tetra-CD, without being a competitive encapsulating site contrarily to what was observed with higher generations of PAMAM. ${ }^{[15]}$ We used 2D ROESY NMR experiments to fully characterize the pristine platform and its inclusion complexes formed with adamantane sodium carboxylate (AdCOONa) and the poorly water-soluble adamantane carboxylic acid (AdCOOH). Adamantane was selected as a model guest molecule because it presents a high association constant with $\beta-C D$ in water, of around $5.10^{4} \mathrm{M}^{-1}$ at room temperature. ${ }^{[16]}$ Besides, diverse molecules that are too voluminous to fit the $\beta-C D$ cavity can be functionalized by an adamantyl moiety, offering them the possibility to be connected to inclusion complexes. ${ }^{[17]}$ Interaction of adamantyl unit with Tetra-CD was discussed in light of results obtained with previously reported trimer and dimer, ${ }^{[18]}$ named here as Tri-CD and Di-CD, respectively, as well as with new monoCDs called $\mathbf{A}$ and $\mathbf{B}$, used as assessment systems. The CD substituents of $\mathbf{A}$ and $\mathbf{B}$ are of similar nature to that of the spacers used for Tri-CD and Di-CD, and for Tetra-CD, respectively (see scheme 1). In that way, comparisons were made independently of the nature of the spacer.

\section{Results and Discussion}

Synthesis and characterization of $\beta C D$-derivatives

The synthetic routes used for the synthesis of the $\beta-C D$ derivatives are summarized in Scheme 1. For the construction of 
Tetra-CD, the tetra-alkyne precursor (III) was prepared via amide bond formation between the amino groups of PAMAM G0 and carboxylic functions of II, using a mixture of EDC. $\mathrm{HCl} / \mathrm{HOBt}$ as coupling reagents. ${ }^{[19]}$ The target molecules Tetra-CD, A and B were obtained using $\mathrm{CuAAC}$ in mild conditions with $\mathrm{Cu}(\mathrm{I})$ as catalyst. Catalytic $\mathrm{Cu}(\mathrm{I})$ species can be generated from $\mathrm{Cu}(0)$ as the source, ${ }^{[20]}$ but also in situ from a mixture of $\mathrm{CuSO}_{4}$ and sodium ascorbate. ${ }^{[21]}$ This last method has been preferred because it excludes the formation of any by-products such as diacetylene and may be even applied in aqueous systems in presence of oxygen. Each compound was isolated in high yield (90 to 98\%) after purification by size exclusion chromatography (SEC). Elemental analyses confirmed the high degree of purity for the obtained compounds, except for an extra-amount of water, namely about 6 water molecules per $\beta-C D$ unit for Tetra-CD, and up to 10 for A and B. All compounds were characterized by electrospray ionisation time-of-flight mass spectrometry (ESITOF-MS).

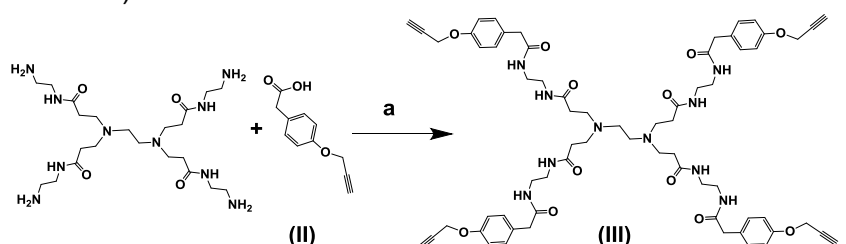<smiles>CCOc1ccc(CC(C)C)cc1</smiles>

The measured masses of the synthesized compounds were found to be in excellent agreement with the calculated ones (see "Experimental Section" part and spectra in ESI). The characterization of the new $\beta$-CD derivatives by NMR techniques $\left({ }^{1} \mathrm{H},{ }^{13} \mathrm{C}, \mathrm{HMQC}, \mathrm{COSY}, \mathrm{NOESY}\right)$ were carried out in detail in DMSO- $d_{6}$ (see text pp. SI-6,7 and corresponding figures). It resulted that a singularity was detected for some protons of the functionalized glucopyranose sub-unit of the $\beta-C D$ cavity (see Scheme 2): protons $\mathrm{H}-1^{\prime}, \mathrm{H}-5^{\prime}$ and $\mathrm{H}-6^{\prime}$ appeared at lower field than their respective correspondents $\mathrm{H}-1, \mathrm{H}-5$ and $\mathrm{H}-6$ of nonfunctionalized sub-units (Figure 1 top). This deshielding effect was particularly marked for $\mathrm{H}-6$ ' protons. There was also a strong impact of the substitution on one $-\mathrm{CH}_{2}-\mathrm{OH}$ fragment of the primary hydroxyl rim, since the signals of protons named as H-6" (two diastereotopic protons resonating at around 3.15 and $2.92 \mathrm{ppm}$ ) and $\mathrm{OH}-6$ " (around $4.30 \mathrm{ppm}$ ) appeared to be significantly upshielded in comparison to their respective analogues $\mathrm{H}-6$ and $\mathrm{OH}$ 6 . Those protons were attributed to a glucopyranose sub-unit contiguous to the substituted one, their up-shielding might result from interaction with the vicinious branch of the molecule. These observations were common to the 3 new compounds for which the CD cavities behave similarly.

Scheme 2. Representations of the CD cavity with atoms numbering $(\mathrm{H}-3$ and $\mathrm{H}-5$ are inner protons, $\mathrm{H}-2$ and $\mathrm{H}-4$ are outer protons).
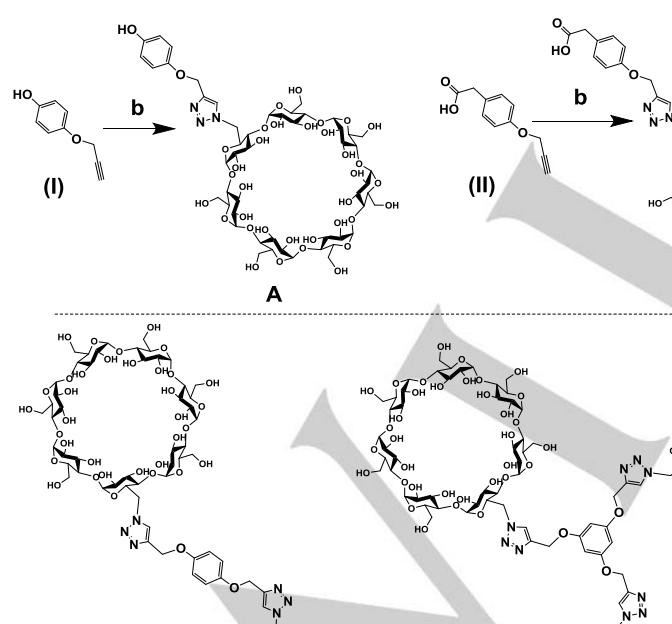

Di-CD

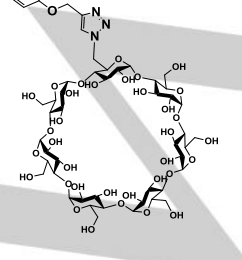

Scheme 1. Top: synthetic routes to the target molecules. a. $\mathrm{EDC} \cdot \mathrm{HCl} / \mathrm{HOBt} / \mathrm{DMF}$, b. $\boldsymbol{\beta C D}-\mathbf{N}_{3}, \mathrm{CuSO}_{4}$ : sodium ascorbate 1:3 / DMSO: $\mathrm{H}_{2} \mathrm{O}$ 5:2 ; Bottom: structures of Di-CD and Tri-CD.

\section{Behaviour of $\beta-C D$ derivatives in water}

The new molecules were then investigated in water, which is the medium of choice for many applications or studies of CD derivatives. ${ }^{[4,22]}$ It is worth to notice that the isolated compounds A and B present good solubilities in water, of $37.5 \mathrm{mg} / \mathrm{mL}$ and $97.4 \mathrm{mg} / \mathrm{mL}$, respectively, in comparison to $18.3 \mathrm{mg} / \mathrm{mL}$ for $\beta$-CD. Moreover, Tetra-CD exhibits remarkable high solubility in water (> $2580 \mathrm{mg} / \mathrm{mL}$ ), which is of about 140 fold higher than that of $\beta$-CD.

The ${ }^{1} \mathrm{H}$ NMR spectrum of the compound Tetra-CD in $\mathrm{D}_{2} \mathrm{O}$ showed a drastic change in the aromatic region, as compared to that obtained from DMSO- $d_{6}$ solution (Figure 1): the integration of the protons signal at around $8 \mathrm{ppm}$, the region where the triazole protons were identified in DMSO, matched only with 2 out of the 20 protons resonating in the 6.5 to $8.2 \mathrm{ppm}$ region. This resulted from the previously observed tumbling process for $C D$ tetramers and dimers in water, ${ }^{[23-25]}$ which affected the triazole protons that now appeared as a multiplet at around $8 \mathrm{ppm}$ (assigned to $\mathrm{H}$-triazole of branches wearing a non-reversed CD cavity) and also as a singlet centred on $7.04 \mathrm{ppm}$ (assigned to the so-called 


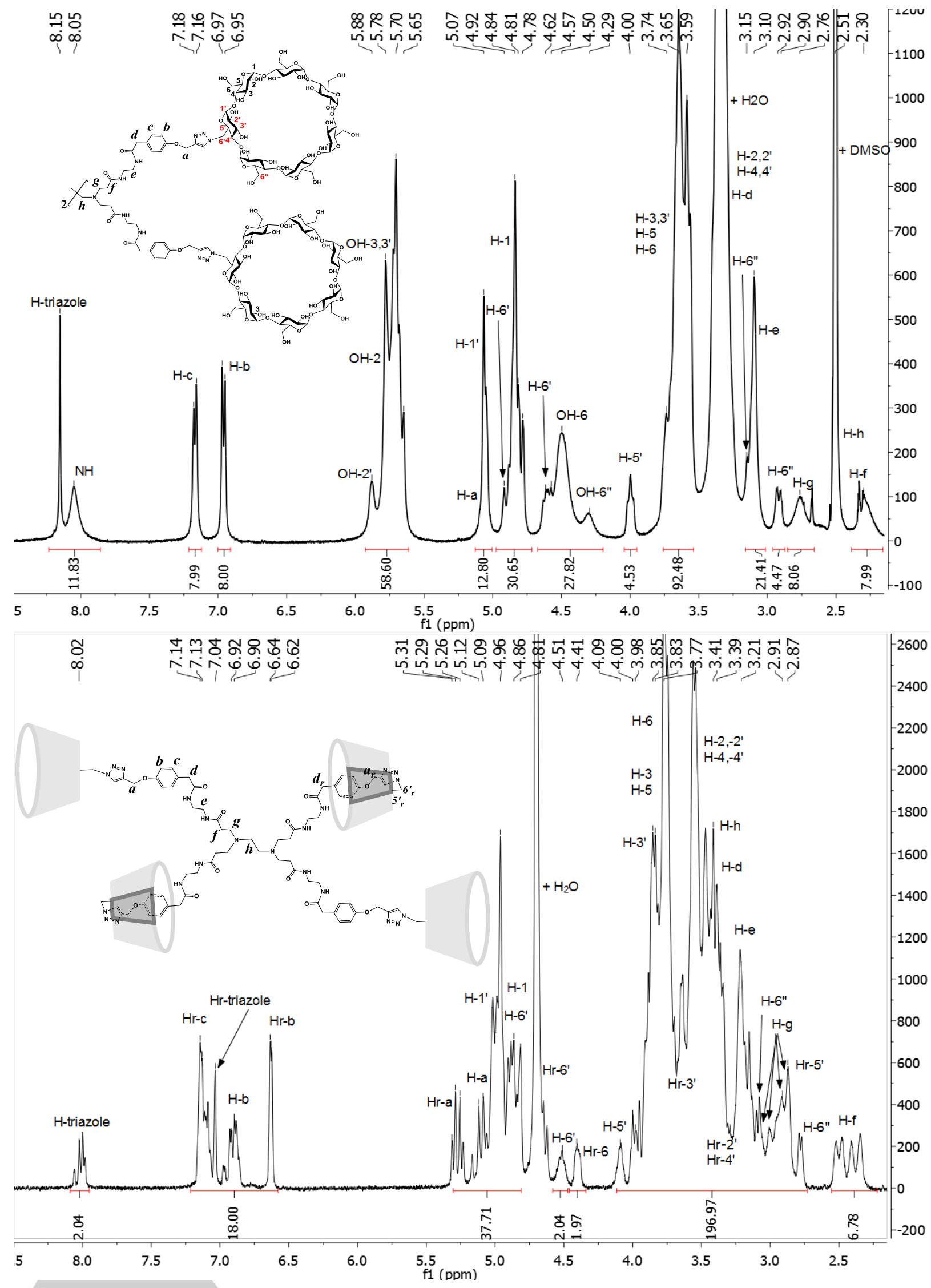

Figure 1. ${ }^{1} \mathrm{H}$ NMR spectrum of compound Tetra-CD. Top: in DMSO- $d_{6}$ with schematic representation of the molecule giving the atoms numbering for CD cavity. Bottom: in $\mathrm{D}_{2} \mathrm{O}$, with the representation of one of the 7 possible forms for compound Tetra-CD in water ("r" stands for the reversed form). 
Hr-triazole of branches wearing a reversed CD cavity). The complexity of the signal at around $8 \mathrm{ppm}$ was explained by the possibility of 7 conformations for compound Tetra-CD in water as sketched below.

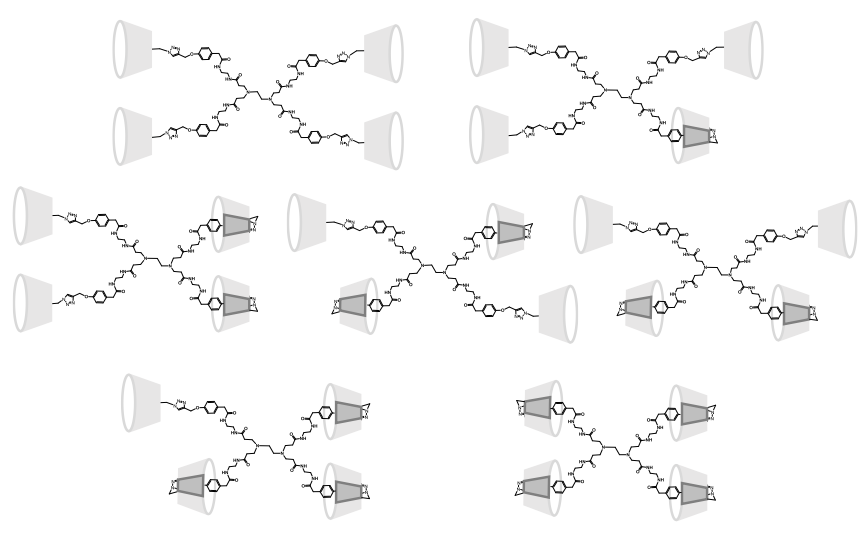

Scheme 3. The 7 possible forms for Tetra-CD with 0 to 4 reversed cavities

The phenyl protons were also disturbed since they did not appear anymore as two doublets but as i) a first massif between 7.05 and $7.2 \mathrm{ppm}$ originating from $\mathrm{H}-\mathrm{C}$ and $\mathrm{Hr}-\mathrm{C}$ aromatic protons of branches wearing a non-reversed and a reversed CD cavity, respectively, ii) a second massif between 6.8 and $7.0 \mathrm{ppm}$ due to the $\mathrm{H}$-b aromatic protons of branches wearing a non-reversed $C D$, and iii) a doublet $(J=7.3 \mathrm{~Hz})$ at $6.63 \mathrm{ppm}$ due to the $\mathrm{Hr}$-b aromatic protons of branches wearing a reversed CD cavity. Integration of the signals indicated that, on average, half of the CD cavities underwent tumbling. Besides these changes observed in the aromatic region when going from DMSO to water, the rest of the spectrum was also affected by the tumbling effect. Assignments of the protons signals were made on the basis of the analysis previously performed in DMSO- $d_{6}$ (see $\mathrm{SI}$ ), with the help of $1 \mathrm{D}$ and 2D NMR experiments in $\mathrm{D}_{2} \mathrm{O}$. Firstly, the 2D COSY spectrum (see Figure SI-25) gave the confirmation for chemical shifts values of aromatic protons and allowed also to assign some other $\mathrm{CD}$ proton signals. For example, the non-equivalent diastereotopic protons $\mathrm{H}-6$ ' of the modified glucopyranose ring of $\beta-C D$ appeared in water as two sets of two signals, one set originating from the non-inverted cavity $(\mathrm{H}-6$ ' centred at around 4.9 and $4.6 \mathrm{ppm}$, respectively), the other from the reversed form $(\mathrm{Hr}-6$ ' centred at around 4.7 and partially hidden by the water peak and $4.4 \mathrm{ppm}$, respectively). The tumbling of the CD cavity resulted in a blending effect for those protons, as it was the case for the Hr-5' protons, detected at around $2.9 \mathrm{ppm}$. Secondly, the HSQC and HMBC spectra (see Figures SI-26 and -27) allowed us to identify most of the protons and carbon signals and also to raise some ambiguities. For example, the $\mathrm{H}$-a protons appeared as two multiplets centred at around 5.3 and $5.1 \mathrm{ppm}$, respectively, correlated with two carbon signals at 62.4 and $61.0 \mathrm{ppm}$, respectively. The comparison with the data for $\mathrm{C}-\mathrm{a} / \mathrm{H}-\mathrm{a}$ in DMSO$d_{6}$ led us to assign the 5.1/61.0 and 5.3/62.4 ppm correlations to $\mathrm{H}-\mathrm{a} / \mathrm{C}-\mathrm{a}$ and $\mathrm{Hr}-\mathrm{a} / \mathrm{Cr}-\mathrm{a}$, respectively. The $\mathrm{C}-\mathrm{d}$ signal was identified at around $41.7 \mathrm{ppm}$ through $\mathrm{HMBC}$ with aromatic $\mathrm{H}$-c protons, thus $\mathrm{H}-\mathrm{d}$ protons were identified at around $3.4 \mathrm{ppm}$. Thirdly, 1D TOCSY experiments (see Figures SI-28 to -30) gave rise to the chemical shifts values of the $\mathrm{H}-\mathrm{f}$ and $\mathrm{H}-\mathrm{g}$ protons of the branches and to those of the protons of the substituted glucopyranose units for reversed and non-reversed CD cavities, as well as to the precise value of the chemical shift of $\mathrm{Hr}-\mathrm{c}$, found to be $7.15 \mathrm{ppm}$. Lastly, 2D ROESY experiment (see Figure SI-31) highlighted specific interactions of $\mathrm{Hr}-\mathrm{a}, \mathrm{Hr}-\mathrm{b}, \mathrm{Hr}-\mathrm{c}$ and $\mathrm{Hr}$-triazole protons with the inner protons of the reversed CD cavity. This fine analysis work led us to propose detailed assignments of the resonance domains of the $C D$ protons (see Figure 1 and Figure SI-32). The ${ }^{13} \mathrm{C}$ NMR spectrum in $\mathrm{D}_{2} \mathrm{O}$ of Tetra-CD evidenced also some changes in comparison to the situation in DMSO- $d_{6}$ since the carbon signals are splitted in water as the result of tumbling. This is particularly apparent for the phenyl and triazolyl carbon signals, which are particularly sensitive to CD tumbling effect (Figure SI33).

The situation was simpler for compounds $\mathbf{A}$ and $\mathbf{B}$ for whose no tumbling was detected in $\mathrm{D}_{2} \mathrm{O}$. Their respective ${ }^{1} \mathrm{H}$ and ${ }^{13} \mathrm{C}$ NMR spectra in $\mathrm{D}_{2} \mathrm{O}$ (see Figures $\mathrm{SI}-34$ and 35 ) exhibited the same features as in DMSO- $d_{6}$. Nevertheless, their 2D NOESY spectra (see Figure SI-36) revealed correlations between phenyl protons and inner protons of $C D$ cavities, indicating interaction between the extremity of the arm of molecule and the CD cavity, as sketched in Figure SI-36, leading to supramolecular assemblies. ${ }^{[26,27]}$

\section{Interaction with adamantane carboxylic acid and its sodium salt}

According to literature, head-to-tail assemblies similar to those observed with compounds $\mathbf{A}$ and $\mathbf{B}$ can be altered by the addition of $\mathbf{A d C O O H}$ that helps in releasing the CD cavity. ${ }^{[26]}$ Besides, the tumbling observed for Tetra-CD could result in an inclusion ability of an average of two molecules of guest per Tetra-CD platform, thus limited accessibility to the CD cavities, ${ }^{[24,25,28]}$ which is of major importance for considering its potential applications in aqueous medium. Due to the high affinity of adamantane for $\beta-C D,{ }^{[16,29]}$ the adamantyl unit (Ad) could be convenient to overcome the tumbling of the CD cavity of Tetra-CD in water.

To clarify this point, we have examined changes in ${ }^{1} \mathrm{H}$ NMR spectra recorded in $\mathrm{D}_{2} \mathrm{O}$ with increasing amounts of $\mathrm{AdCOONa}$ relative to Tetra-CD. The results were numbered using the molar fraction $X_{C D}=[\beta-C D] /([\beta-C D]+[A d C O O N a])$, for simplicity reasons (see Figure 2). For a $0.9 \mathrm{X}_{C D}$ molar fraction, the spectrum shape was similar to that obtained for pure Tetra-CD in $\mathrm{D}_{2} \mathrm{O}$, unless a slight increase in integration for $\mathrm{H}$-triazole protons (centred on 8 $\mathrm{ppm}$ ) relatively to the total 20 protons resonating from 6.5 to 8.2 $\mathrm{ppm}$. As $X_{\mathrm{CD}}$ decreased, the spectrum shape became simpler with the decrease of the multiplicity for the triazole and $\mathrm{H}-\mathrm{b}$ protons, concomitant with the progressive disappearance of the $\mathrm{Hr}-\mathrm{b}$ signal. As soon as $X_{C D}$ reached 0.5 , the signal of triazole proton looked as a singlet at $7.96 \mathrm{ppm}$, and that of phenyl protons as two doublets $(J=8.8 \mathrm{~Hz})$ at 7.1 and $6.9 \mathrm{ppm}$, respectively, in a similar way to what was observed for pure Tetra-CD in DMSO-d6. This was interpreted as the total disappearance of reversed form of cyclodextrin.

Analyses of those mixtures by 2D ROESY NMR spectroscopy revealed also drastic changes upon addition of AdCOONa. The reference ROESY spectrum of pristine Tetra-CD in $D_{2} \mathrm{O}$, given in Figure SI-37, displayed interactions of $\mathrm{Hr}$-triazole, $\mathrm{Hr}-\mathrm{a}, \mathrm{Hr}-\mathrm{b}$, and $\mathrm{Hr}-\mathrm{C}$, with inner protons of reversed $\mathrm{CD}$ cavity. Conversely, when $X_{C D}$ was set at 0.1 , i.e. in the presence of a large excess of AdCOONa, only cross-peaks between the protons of CD cavity $\left(\mathrm{H}-3,3^{\prime} ; \mathrm{H}-5,5^{\prime}\right)$ and those of AdCOONa $(\mathrm{H}-\alpha ; \mathrm{H}-\beta ; \mathrm{H}-\gamma)$ were observed, which indicates that the $\mathrm{CD}$ cavities hosted only 
AdCOONa molecules (see Figure SI-38). The absence of NOE effect involving triazole and aromatic protons suggests that no $C D$ cavity remained in reversed conformation. Intermediate cases for which $\mathrm{X}_{\mathrm{CD}}$ ranged from 0.8 to 0.4 are shown in Figures SI-39 to 42. For $X_{C D}=0.8$, the internal protons of the $C D$ cavities displayed $\mathrm{NOE}$ with triazole, aromatic and $\mathrm{Hr}$-a protons, as well as with adamantyl protons: the interaction with inner CD protons occurred for both inverted and non-inverted $C D$ rings. For a molar fraction of 0.6 , inclusion occurrence was more pronounced, with intense correlation peaks in the 1.5-2 ppm region, in comparison to what was observed in the aromatic region. Correlation with $\mathrm{Hr}$-a protons was no more seen. As $X_{C D}$ reached 0.5 , correlations involving inner $C D$ protons were exclusively seen with adamantyl $\mathrm{H}-\alpha, \mathrm{H}-\beta$, and $\mathrm{H}-\mathrm{\gamma}$ protons; the same observation was made for $\mathrm{X}_{\mathrm{CD}}=0.4$ (Figure SI-40). The use of AdCOOH as the guest led to same observations (see Figure SI-43). The apparent diffusion coefficients of adamantane carboxylate and adamantane carboxylic acid in the examined mixtures were evaluated through ${ }^{1} \mathrm{H}$ DOSY NMR experiments. The results, gathered in Table 1, indicated that as long as adamantyl unit was in default with respect to cyclodextrin, i.e. until a $X_{C D}$ value of 0.5 , its diffusion coefficient $(D)$ value was low and rather constant, due to its inclusion into the $C D$ cavity. Upon decreasing $X_{C D}$, a progressive increase in $D$ value was observed, due to increasing amounts of free adamantane species in solution, until a maximum corresponding to these pure compounds. To summarize, beyond an equimolar ratio of adamantyl unit and cyclodextrin, no tumbling was detected by NMR spectroscopy and an increase in apparent value of $D$ was measured. This could be indicative of formation of a [1:4] [Tetra-CD:Ad] complex.

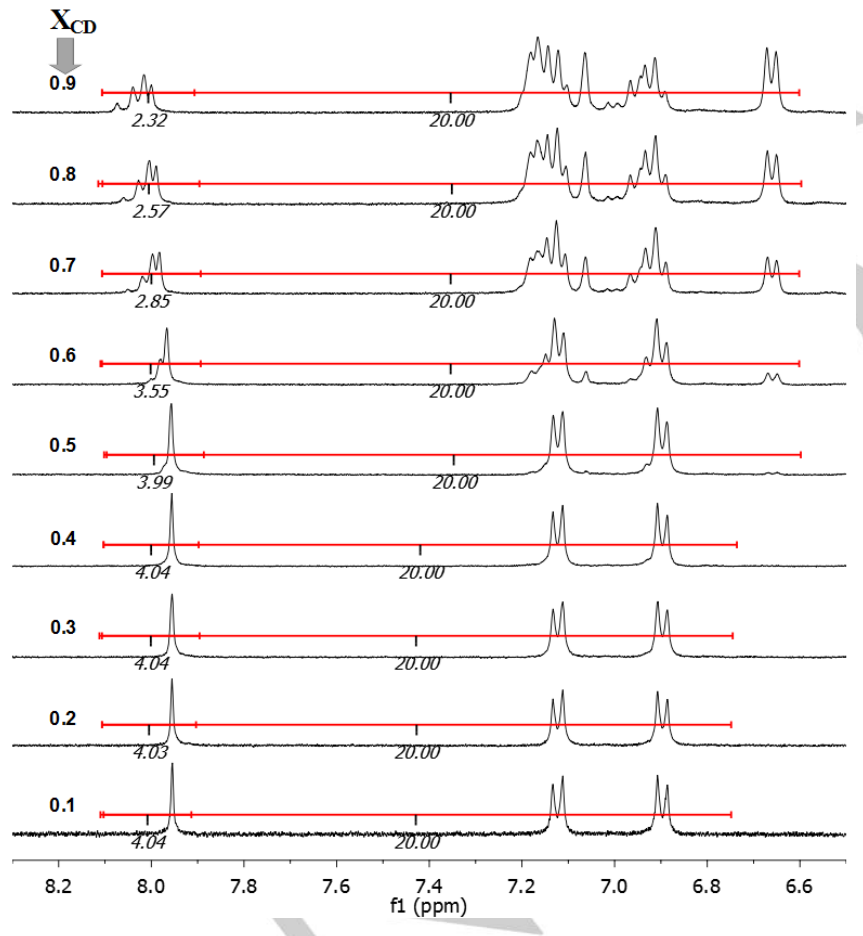

Figure 2. Evolution from top to bottom of ${ }^{1} \mathrm{H}$ NMR spectra in the 6.5-8.3 ppm region of mixtures of Tetra-CD and AdCOONa in $\mathrm{D}_{2} \mathrm{O}$ with decreasing molar fraction, expressed with respect to the concentration in $\beta-C D$ cavities $\left(\mathrm{X}_{\mathrm{CD}}=[\boldsymbol{\beta}-\mathrm{CD}] /([\boldsymbol{\beta}-\mathrm{CD}]+[\mathrm{AdCOONa}])\right.$. Italic: protons integration over the red segments domains. Total concentration $[\boldsymbol{\beta}-\mathrm{CD}]+[\mathrm{AdCOONa}]=8 \mathrm{mmol} \cdot \mathrm{L}^{-1}$.
For evaluating the complex stoichiometry with adamantane carboxylate salt, Job's plot analyses were performed on compounds $\mathbf{A}$ and Tetra-CD. The cases of the so-called Di-CD and Tri-CD were also examined. These last molecules were chosen as comparison compounds, because the structure of their spacers was similar to that of compound $\mathbf{A}$, and they constituted intermediate cases in between $\mathbf{A}$ and Tetra-CD: $\mathbf{D i}-\mathbf{C D}$ is a dimer for which it was found that the tumbling process occurred for $90 \%$ of molecules in water, ${ }^{[24]}$ whereas Tri-CD underwent no reversion process for steric reasons as demonstrated by the presence of ${ }^{1} \mathrm{H}$ NMR singlets in $\mathrm{D}_{2} \mathrm{O}$ at 8.15 and 6.42 ppm, originating from 3 triazolyl and 3 phenyl protons, respectively. ${ }^{[18]}$ Figure SI-44 shows the continuous-variation plots of the ${ }^{1} \mathrm{H}$ NMR chemical shift change for the four compounds. For each case, a maximum value was obtained at $X_{C D}=0.5$, which indicated the formation of a [1:1] complex, as expressed with regards to $C D$ cavities. It followed that compounds A and Tri-CD lead in water, to [A:AdCOONa] and [Tri-CD:AdCOONa] complexes which stoichiometries are [1:1] and [1:3], respectively, as logically awaited, and [Di-CD:AdCOONa] and [Tetra-CD:AdCOONa] complexes exhibited respective stoichiometries of [1:2] and [1:4]. This set of analyses, based on NMR experiments, led us to the assumption that, even in presence of reversed CD cavities in the starting water solutions, it was possible to make them available for inclusion phenomena, thanks to shifting of the tumbling process by using the strongly affine host adamantyl unit.

In order to confirm the possibility for those two molecules to involve all $C D$ cavities in inclusion phenomena, we have examined their isolated inclusion complexes (see Experimental part) by mass spectrometry (MS) with electrospray ionization (ESI) from $\mathrm{MeOH} / \mathrm{H}_{2} \mathrm{O}$ solutions. Compounds $\mathbf{A}$ and $\mathbf{B}$ led to complexes which weights were compatible with MS-ESI detection in positive mode. The molecular peak for $\mathbf{A}$ was detected at $\mathrm{m} / \mathrm{z}$ $=1308.4\left(55 \%,[\mathrm{MH}]^{+}\right)$, along with its sodium adduct at $\mathrm{m} / \mathrm{z}=$ $1330.4\left(100 \%,[\mathrm{M}+\mathrm{Na}]^{+}\right)$(see Figure Sl-45). The mass spectrum revealed also the signal of the [1:1] inclusion complex at $\mathrm{m} / \mathrm{z}=$ $1510.5\left(73 \%\right.$, $\left.[\mathrm{M}+\mathrm{AdCOOH}+\mathrm{Na}]^{+}\right)$, and others corresponding to multi-charged species resulting to higher inclusion compounds, based on 2 up to 3 molecules $\mathbf{A}$ supposed to be included in cascade. Similar species were observed with complex formed from B, i.e. molecules B itself, [1:1] complex of [B:AdCOOH], and related molecules included in cascade (see Figure SI-46). Note for $\mathbf{B}$ complex analysis the $100 \%$ abundance for the peak at $\mathrm{m} / \mathrm{z}=1552.6$ corresponding to the $[\mathrm{M}+\mathrm{AdCOOH}+\mathrm{Na}]^{+}$complex. Note also that, except for pristine $\mathbf{A}$ and $\mathbf{B}$ molecules, peaks of significant abundance always correspond to species for whose the CD cavity is hosting an adamantane molecule. Thus, as previously reported in literature, ${ }^{[27]}$ the formation of supramolecular assemblies due to head-to-tail interactions is not a major inconvenience for getting [1:1] complexes for compounds $\mathbf{A}$ and $\mathbf{B}$. We also examined inclusion complex formed from Di-CD in the same conditions. MS-ESI analysis in the positive mode (see Figure SI-47) afforded the molecular peak for Di-CD at $\mathrm{m} / \mathrm{z}=$ $1275.9[\mathrm{M}+2 \mathrm{Na}]^{2+}$. The presence of [1:2] complex was detected by zooming in the $\mathrm{m} / \mathrm{z} 1400-1500$ zone as multicharged species forming adducts with sodium or potassium cations. Interestingly, MS-ESI in the negative mode revealed to be an efficient techniques for detecting more obviously this [1:2] complex as showed in Figure SI-48. The peak at $\mathrm{m} / \mathrm{z}=1432$ (92\% abundant) was identified as the di-charged $[\mathrm{M}-2 \mathrm{H}+2 \mathrm{AdCOOH}]^{2-}$ complex whereas that at $\mathrm{m} / \mathrm{z}=954.3$ ( $10 \%$ abundant) was related to the 
tri-charged complex. [Tetra-CD:AdCOOH] revealed also suitable for MS-ESI analysis from water solution in the negative mode: the peak at $\mathrm{m} / \mathrm{z}=1640.6$ (12\% abundant) was attributed to the [1:4] complex appearing as tetra-charged species $[\mathrm{M}-4 \mathrm{H}+4 \mathrm{AdCOOH}]^{4-}$ [see Figure SI-49]. These last results suggest the possibility for the $C D$ cavities to be fully available for hosting adamantane derivatives, despite their initial reversed conformation in water.

Table 1. Diffusion coefficients in $\mathrm{D}_{2} \mathrm{O}$ of $\mathrm{AdCOONa}$ and $\mathrm{AdCOOH}$, pure or in mixture with Tetra-CD, measured by ${ }^{1} \mathrm{H}$ DOSY NMR technique. The composition of the mixtures is given by $\mathrm{X}_{\mathrm{CD}}$. Total concentration $[\beta-C D]+[A d]=8 \mathrm{mML}^{-1}$

\begin{tabular}{lcccccc}
\hline $\mathrm{X}_{\mathrm{CD}}$ & 0.8 & 0.6 & 0.5 & 0.4 & 0.1 & 0 \\
\hline$D_{\text {AdCOONa }}\left(10^{-10} \mathrm{~m}^{2} / \mathrm{s}\right)$ & 1.0 & 1.0 & 1.3 & 2.4 & 3.8 & 4.2 \\
$D_{\text {AdCOOH }}\left(10^{-10} \mathrm{~m}^{2} / \mathrm{s}\right)$ & 1.2 & 1.2 & 1.8 & 1.9 & 2.9 & 5.8 \\
\hline
\end{tabular}

\section{Conclusion}

There are several reports on $\beta$-CD-based platforms used as drug carriers, particularly those obtained from grafting high molecularweight polymers on primary/secondary face of the $\beta-C D .{ }^{30}$ One drawback of this strategy is that the polymer chains may compete with other guests and occupy the inner space of the $\beta-C D$ cavity, ${ }^{[31]}$ limiting the host-guest interaction that causes a lower drug load. Therefore, we synthesized a highly water-soluble PAMAM $\beta-C D$ derivative, Tetra-CD, initially thought to eliminate such host-host competition. We demonstrated that, despite the occurrence of tumbling in water, it was possible to form [1:4] inclusion complexes with adamantyl species in that medium. It results that the tumbling effect reported in literature ${ }^{[23-25]}$ can be efficiently shifted in the presence of an appropriate hydrophobic guest, resulting in the full host-ability of the CD units in water. This strategy is an encouraging alternative for the modification of PAMAM with carbohydrates ${ }^{[32]}$ which can help in mitigating the toxicity already known for low PAMAM generations. ${ }^{[33]}$ This tetramer combines thus high solubility, multiple functions surface of PAMAM dendrimer, and inclusion properties of $\beta-C D$, making it promising for drug loading purpose. ${ }^{[34]}$ Works in that aim are in progress.

\section{Experimental Section}

General: 4-(Propargyloxy)phenol (I), ${ }^{[35]}$ 2-[4-(propargyloxy)phenyl]acetic acid (II), ${ }^{[36]}$ 6-O-monotosyl- $\beta$-cyclodextrin ( $\beta$-CD-OTs) ${ }^{[37]}, 6$-O-monoazido$\beta$-cyclodextrin $\left(\boldsymbol{\beta}-\mathbf{C D}-\mathbf{N}_{3}\right),{ }^{[11]}$ and the two platforms Di-CD and Tri-CD, were synthesized according to literature. ${ }^{[18]}$ All starting materials were purchased from Aldrich, Acros, Fluka and Strem. 1-Ethyl-3-(3dimethylaminopropyl) carbodiimide hydrochloride (EDC. $\mathrm{HCl}), \quad \mathrm{N}$ hydroxybenzotriazole ( $\mathrm{HOBt})$, PAMAM GO dendrimer, copper sulfate $\left(\mathrm{CuSO}_{4}\right)$ and solvents were used as received. Sodium-ascorbate was freshly recrystallized from a water:ethanol mixture. Distilled water was used in all experiments. Reactions were performed under argon atmosphere and monitored by analytical TLC on pre-coated silica gel 60 F254 plates (Aldrich) with detection carried out under UV light. Purifications by column chromatography were performed on silica gel 60$200 \mu \mathrm{m}$ VWR CHEMICALS. Size Exclusion Chromatography (SEC) was performed using water as the eluent with resins Bio-Gel $\AA^{\circledR}$ P-6 medium
(BIO-RAD Laboratory) and Sephadex G-15 (Aldrich). ${ }^{1} \mathrm{H},{ }^{13} \mathrm{C}$ NMR and 2D HMQC, COSY, NOESY, ROESY, TOCSY experiments were obtained at $298 \mathrm{~K}$ on Bruker spectrometers (AV $400 \mathrm{MHz}$, Bruker Avance 500 spectrometer equipped with a $5 \mathrm{~mm}$ triple resonance inverse Z-gradient probe $\left(\mathrm{TBI}{ }^{1} \mathrm{H},{ }^{31} \mathrm{P}, \mathrm{BB}\right)$ and Bruker NEO 600 spectrometer equipped with a $5 \mathrm{~mm}$ triple resonance inverse $\mathrm{Z}$-gradient probe $\left(\mathrm{TBI}{ }^{1} \mathrm{H},{ }^{31} \mathrm{P}, \mathrm{BB}\right)$ ). All spectra were recorded at $25^{\circ} \mathrm{C}$ in the indicated deuterated solvents. Chemical shifts are reported in ppm ( $\delta$ ) and coupling constants $(\mathcal{J})$ are reported in $\mathrm{Hz}$. Multiplicities are reported by using the following abbreviations: $\mathrm{s}=$ singlet, $\mathrm{d}=$ doublet, $\mathrm{t}=$ triplet, $\mathrm{br}=$ broad, and $\mathrm{m}=$ multiplet. Protons and carbons signal assignments are indicated on the spectra reported in SI. Mass spectrometry was performed by the Mass Spectrometry Core Facility of ICT; ESI-TOF experiments have been made on a Q-TOF Premier spectrometer (Waters in positive and negative ionisation modes, using direct introduction. HR-ESI-TOF experiments have been made on a Q-TOF Premier (Waters) and on a Xevo G2 QTOF (Waters).

\section{Synthesis}

PAMAM G0-alkyne (III): According to a slightly modified general protocol, ${ }^{[19]}$ a mixture of compound II $(515 \mathrm{mg}, 2.7 \mathrm{mmol}), \mathrm{EDC} \cdot \mathrm{HCl}(727$ $\mathrm{mg}, 3.79 \mathrm{mmol})$, and $\mathrm{HOBt}(366 \mathrm{mg}, 2.7 \mathrm{mmol})$ in DMF (14 mL) was stirred for $4 \mathrm{~h}$ at room temperature. Then, a solution of PAMAM G0 $(250 \mathrm{mg}, 0.483$ $\mathrm{mmol}$ ) in DMF (2 $\mathrm{mL})$ was added dropwise. The resulting mixture was kept under stirring for 3 days at $35^{\circ} \mathrm{C}$. After evaporation of the solvent under vacuum, the resulting solid was recrystallized in methanol, affording PAMAM G0-alkyne as a white powder ( $571 \mathrm{mg}, 0.473 \mathrm{mmol}$, yield $98 \%$ ). ${ }^{1} \mathrm{H}$ NMR $(400 \mathrm{MHz}$, DMSO-d $6, \delta \mathrm{ppm}): 8.03(\mathrm{br}, 4 \mathrm{H}, \mathrm{NH}), 7.96(\mathrm{br}, 4 \mathrm{H}, \mathrm{NH})$, $7.16(\mathrm{~d}, J=8.7 \mathrm{~Hz}, 8 \mathrm{H}, \mathrm{H}-\mathrm{c}), 6.90(\mathrm{~d}, J=8.7 \mathrm{~Hz}, 8 \mathrm{H}, \mathrm{H}-\mathrm{b}), 4.75(\mathrm{~d}, J=2.4$ $\mathrm{Hz}, 8 \mathrm{H}, \mathrm{H}-\mathrm{a}), 3.53(\mathrm{tr}, \mathrm{J}=2.4 \mathrm{~Hz}, 4 \mathrm{H}, \mathrm{C} \equiv \mathrm{H}), 3.33(8 \mathrm{H}, \mathrm{H}-\mathrm{d}$ overlapped with $\mathrm{H}_{2} \mathrm{O}$ ), 3.08 (br, 16H, H-e), $2.65(\mathrm{~m}, 8 \mathrm{H}, \mathrm{H}-\mathrm{g}), 2.45(\mathrm{br}, 4 \mathrm{H}, \mathrm{H}-\mathrm{h}), 2.19(\mathrm{~m}$, $8 \mathrm{H}, \mathrm{H}-\mathrm{f}) ;{ }^{13} \mathrm{C}\left\{{ }^{1} \mathrm{H}\right\}$ NMR $\left(101 \mathrm{MHz}, \mathrm{DMSO}-d_{6}, \delta \mathrm{ppm}\right): 171.95,171.02$, $156.26,130.41,129.49,115.03,79.84,78.54,55.80,51.25,50.04,41.92$ 38.98, 38.73, 33.60. ESI-TOF-MS m/z = 1205.5 (calcd. 1205.6 for $[\mathrm{MH}]^{+}$); 1227.5 (calcd. 1227.6 for $[\mathrm{MNa}]^{+}$). Elemental analysis: calculated for $\mathrm{C}_{66} \mathrm{H}_{80} \mathrm{~N}_{10} \mathrm{O}_{12}+1 \mathrm{H}_{2} \mathrm{O}$ : C: $64.80 ; \mathrm{H}: 6.76 ; \mathrm{N}: 11.45 ; \mathrm{O}: 17.00$; found C: 64.63; H: 6.77; N: 11.72; O: 16.22 .

Compound Tetra-CD: PAMAM-G0 alkyne $(130 \mathrm{mg}, 0.107 \mathrm{mmol})$ and $\beta-C D-N_{3}(550 \mathrm{mg}, 0.474 \mathrm{mmol})$ were dissolved in DMSO $(5 \mathrm{~mL})$ previously degassed by argon bubbling for $15 \mathrm{~min}$. A solution of $\mathrm{CuSO}_{4}(8 \mathrm{mg}, 0.047$ $\mathrm{mmol}$ ) in $0.5 \mathrm{~mL}$ of $\mathrm{H}_{2} \mathrm{O}$, followed by a solution of sodium ascorbate (28 $\mathrm{mg}, 0.142 \mathrm{mmol})$ in $\mathrm{H}_{2} \mathrm{O}(0.5 \mathrm{~mL})$ added dropwise over $5 \mathrm{~min}$. The mixture immediately turned yellow, and then was heated at $80^{\circ} \mathrm{C}$ under vigorous stirring for $48 \mathrm{~h}$ under argon atmosphere. After cooling down to room temperature, the mixture was precipitated in an excess of acetone (130 $\mathrm{mL}$ ), giving a yellow powder recovered by filtration on a glass filter. The powder was dissolved in water and purified by SEC (Bio-Gel@ P-6 medium). Evaporation of the solvent gave a pale yellow powder $(579 \mathrm{mg}$, $0.099 \mathrm{mmol}$, yield $92.5 \%) .{ }^{1} \mathrm{H}$ NMR $\left(400 \mathrm{MHz}\right.$, DMSO- $\left.d_{6}, \delta \mathrm{ppm}\right): 8.15$ (s, $4 \mathrm{H}, \mathrm{H}$ triazole), $8.05(\mathrm{~s}, 8 \mathrm{H}, \mathrm{NH}), 7.17(\mathrm{~d}, J=8.1 \mathrm{~Hz}, 8 \mathrm{H}, \mathrm{H}-\mathrm{c}), 6.96(\mathrm{~d}, J=$ $8.1 \mathrm{~Hz}, 8 \mathrm{H}, \mathrm{H}-\mathrm{b}), 5.88$ (s, 4H, OH-2'), $5.78(\mathrm{~s}, 24 \mathrm{H}, \mathrm{OH}-2), 5.74-5.60(\mathrm{~m}$ $\left.28 \mathrm{H}, \mathrm{OH}-3,3^{\prime}\right), 5.18-5.00$ (m, 12H, H-1'; H-a), 4.95-4.75 (m, 28H, H-6'; H1), 4.67- 4.20 (m, $\left.28 \mathrm{H}, \mathrm{H}-6^{\prime}, \mathrm{OH}-6, \mathrm{OH}-6^{\prime \prime}\right), 4.00\left(\mathrm{~m}, 4 \mathrm{H}, \mathrm{H}-5^{\prime}\right), 3.83-3.50$ (m, 92H, H-6, H-3,3', H-5), 3.50-3.20 (m, $56 \mathrm{H}, \mathrm{H} 4,4^{\prime}, \mathrm{H}-2,2^{\prime}$ overlapped with $\mathrm{H}_{2} \mathrm{O}$ ), 3.20-3.05 (m, 20H, H-6"; H-e), 2.91 (m, 4H, H-6"), 2.76 (s, 8H, $\mathrm{H}-\mathrm{g}), 2.55-2.46(\mathrm{~m}, 12 \mathrm{H}, \mathrm{H}-\mathrm{d}, \mathrm{H}-\mathrm{h}$ overlapped with DMSO), $2.30(\mathrm{~m}, 8 \mathrm{H}$, $\mathrm{H}-\mathrm{f}) ;{ }^{13} \mathrm{C}\left\{{ }^{1} \mathrm{H}\right\}$ NMR (101 MHz, DMSO- $\left.d_{6}, \delta \mathrm{ppm}\right): 171.93,171.14,157.22$, $143.00,130.48,128.98,125.94,114.86,102.38,102.04,101.74,83.43$, $81.99,73.50,72.86,70.64,61.39,60.21,51.54,51.52,50.76,41.92,38.74$, 33.43. ESI-TOF-MS $\mathrm{m} / \mathrm{z}=1963.8$ (calcd. 1964.0 for $\left[\mathrm{MHNa}_{2}\right]^{3+} ; 1478.6$ (calcd. 1478.8 for $\left[\mathrm{MHNa}_{3}\right]^{4+}$. Elemental analysis calculated for $\mathrm{C}_{234} \mathrm{H}_{356} \mathrm{~N}_{22} \mathrm{O}_{148}+25 \mathrm{H}_{2} \mathrm{O}$ C: $44.64 ; \mathrm{H}: 6.50 ; \mathrm{N}: 4.89 ; \mathrm{O}: 43.96$; found $\mathrm{C}$ : 43.65; H: 6.31; N: 4.80; O: 43.30 .

Compound A: Compound I ( $70.2 \mathrm{mg}, 0.47 \mathrm{mmol})$ and $\boldsymbol{\beta}$-CD- $\mathbf{N}_{3}(500 \mathrm{mg}$, $0.43 \mathrm{mmol}$ ) was dissolved in DMSO $(5 \mathrm{~mL})$ previously degassed by argon bubbling for $15 \mathrm{~min}$. To a solution of compound I ( $70.2 \mathrm{mg}, 0.47 \mathrm{mmol}$ ) and 
$\beta$-CD- $\mathbf{N}_{3}(500 \mathrm{mg}, 0.43 \mathrm{mmol}$ ) dissolved in $5 \mathrm{~mL}$ of DMSO degassed by argon bubbling for $15 \mathrm{~min}$, solutions of $\mathrm{CuSO}_{4}(15 \mathrm{mg}, 0.094 \mathrm{mmol})$ in 1 $\mathrm{mL}$ of $\mathrm{H}_{2} \mathrm{O}$, then sodium ascorbate ( $56 \mathrm{mg}, 0.282 \mathrm{mmol}$ ) in $1 \mathrm{~mL}$ of $\mathrm{H}_{2} \mathrm{O}$, were added dropwise. The mixture turned rapidly yellow and was heated at $50{ }^{\circ} \mathrm{C}$ with vigorous stirring for $24 \mathrm{~h}$. After cooling down to room temperature, the mixture was precipitated in an excess of acetone $(80 \mathrm{~mL})$. A green powder was recovered by filtration and then purified by SEC (Sephadex-G15). Evaporation of the solvent gave a pale yellow powder (507 mg, $0.39 \mathrm{mmol}$, yield $90 \%$ ). ${ }^{1} \mathrm{H}$ NMR $\left(400 \mathrm{MHz}\right.$, DMSO- $d_{6}, \delta \mathrm{ppm}$ ): $8.94(\mathrm{~s}, 1 \mathrm{H}, \mathrm{H}$-phenol), $8.12(\mathrm{~s}, 1 \mathrm{H}, \mathrm{H}$-triazole), $6.85(\mathrm{~d}, J=9.0 \mathrm{~Hz}, 2 \mathrm{H}, \mathrm{H}$ b), $6.68(\mathrm{~d}, J=9.0 \mathrm{~Hz}, 2 \mathrm{H}, \mathrm{H}-\mathrm{c}), 5.90-5.60(\mathrm{~m}, 14 \mathrm{H}, \mathrm{OH}-2-2$ '; OH-3,3'), $5.04\left(\mathrm{~s}, 1 \mathrm{H}, \mathrm{H}-1^{\prime}\right), 4.97(\mathrm{~s}, 2 \mathrm{H}, \mathrm{H}-\mathrm{a}), 4.99-4.75(\mathrm{~m}, 7 \mathrm{H}, \mathrm{H}-6$ '; H-1), 4.65$4.55\left(\mathrm{~m}, 1 \mathrm{H}, \mathrm{H}-6^{\prime}\right), 4.55-4.40(\mathrm{~m}, 5 \mathrm{H}, \mathrm{OH}-6), 4.28\left(\mathrm{~m}, 1 \mathrm{H}, \mathrm{OH}-6{ }^{\prime \prime}\right), 4.00(\mathrm{~m}$, $\left.1 \mathrm{H}, \mathrm{H}^{\prime} 5^{\prime}\right), 3.75-3.50$ (m, 23H, H-6; H-3,3'; H-5), 3.48-3.20 (m, 14H, H-4,4', $\mathrm{H}-2,2^{\prime}$ overlapped with $\left.\mathrm{H}_{2} \mathrm{O}\right), 3.11(\mathrm{~m}, 1 \mathrm{H}, \mathrm{H}-6 "), 2.93(\mathrm{~m}, 1 \mathrm{H}, \mathrm{H}-6 ") ;{ }^{13} \mathrm{C}$ $\left\{{ }^{1} \mathrm{H}\right\}$ NMR $\left(101 \mathrm{MHz}\right.$, DMSO- $\left.d_{6}, \delta \mathrm{ppm}\right): 152.08,151.33,143.35,125.68$, $116.21,116.14,102.67,102.49,102.45,102.36,101.72,83.90,82.52$, $81.97,81.82,81.45,73.67,73.45,73.10,72.95,72.82,72.50,72.21,70.42$ $60.39,60.30,61.98,60.61,60.42,59.44,50.79$. HR-ESI-TOF-MS m/z = $1308.4429[\mathrm{MH}]^{+}, 1330.4265[\mathrm{MNa}]^{+}$. Elemental analysis: calculated for $\mathrm{C}_{51} \mathrm{H}_{77} \mathrm{~N}_{3} \mathrm{O}_{36}+9 \mathrm{H}_{2} \mathrm{O}: \mathrm{C}: 41.66 ; \mathrm{H}: 6.51 ; \mathrm{N}: 2.86 ; \mathrm{O}: 48.97$; found $\mathrm{C}: 41.55$; $\mathrm{H}: 6.50 ; \mathrm{N}: 2.49$; O: 43.21 .

Compound B: The same procedure for the obtainment of compound $\mathbf{A}$ was used, starting from Compound II $\left(90 \mathrm{mg}, 0.47 \mathrm{mmol}\right.$ ) and $\boldsymbol{\beta}-\mathbf{C D}-\mathbf{N}_{3}$ $(500 \mathrm{mg}, 0.43 \mathrm{mmol}$ ). The obtained powder was purified by SEC (Bio-Gel 8 P-6 medium). Evaporation of the solvent gave a pale yellow powder (569 $\mathrm{mg}, 42 \mathrm{mmol}$, yield $98 \%){ }^{1} \mathrm{H}$ NMR $\left(400 \mathrm{MHz}\right.$, DMSO- $\left.d_{6}, \delta \mathrm{ppm}\right): 12.03$ (s, $1 \mathrm{H}, \mathrm{COOH}), 8.16(\mathrm{~s}, 1 \mathrm{H}, \mathrm{H}$ triazole), $7.18(\mathrm{~d}, J=8.0 \mathrm{~Hz}, 2 \mathrm{H}, \mathrm{Hc}), 6.98(\mathrm{~d}$, $J=8.0 \mathrm{~Hz}, 2 \mathrm{H}, \mathrm{Hb}$ ), $5.88\left(\mathrm{~d}, J=8.0 \mathrm{~Hz}, 1 \mathrm{H}, \mathrm{OH}-2^{\prime}\right), 5.78(\mathrm{~s}, 6 \mathrm{H}, \mathrm{OH}-2)$, 5.75-5.55 (m, 7H, OH-3,3'), $5.08(\mathrm{~s}, 2 \mathrm{H}, \mathrm{Ha}), 5.05\left(\mathrm{~s}, 1 \mathrm{H}, \mathrm{H}-1^{\prime}\right), 5.00-4.70$ (m, 7H, H-6'; H-1), $4.61\left(\mathrm{~m}, 1 \mathrm{H}, \mathrm{H}-6^{\prime}\right), 4.55-4.40(\mathrm{~m}, 5 \mathrm{H}, \mathrm{OH}-6), 4.29$ (s, $\left.1 \mathrm{H}, \mathrm{OH}-6^{\prime \prime}\right), 4.00\left(\mathrm{~m}, 1 \mathrm{H}, \mathrm{H}-5^{\prime}\right), 3.80-3.45\left(\mathrm{~m}, 23 \mathrm{H}, \mathrm{H}-6, \mathrm{H}-3,3^{\prime}, \mathrm{H}-5\right), 3.45-$ $3.25\left(\mathrm{~m}, 14 \mathrm{H}, \mathrm{H}-4,4^{\prime}, \mathrm{H}-2,2^{\prime}\right.$ overlapped with $\left.\mathrm{H}_{2} \mathrm{O}\right), 3.25-3.10(\mathrm{~m}, 1 \mathrm{H}, \mathrm{H}-$ 6"), $2.91(\mathrm{~m}, 1 \mathrm{H}, \mathrm{H}-6 "), 2.55\left(\mathrm{~s}, 2 \mathrm{H}, \mathrm{Hd}\right.$ overlapped with $\left.\mathrm{H}_{2} \mathrm{O}\right) ;{ }^{13} \mathrm{C}\left\{{ }^{1} \mathrm{H}\right\}$ NMR $\left(101 \mathrm{MHz}\right.$, DMSO- $\left.d_{6}, \delta \mathrm{ppm}\right): 173.45,157.35,143.02,130.85$, $127.75,125.92,114.90,102.66,102.35,101.73,83.90,82.51,81.98$, $81.82,81.47,73.66,73.45,73.29,73.10,72.87,72.81,72.50,72.20,70.44$, $61.37,60.29,59.44,50.82, \sim 40.00$ (overlap with DMSO). HR-ESI-TOF-MS $\mathrm{m} / \mathrm{z} 1350.4503[\mathrm{MH}]^{+}, 1372.4316[\mathrm{MNa}]^{+}$. Elemental analysis calculated for $\mathrm{C}_{53} \mathrm{H}_{79} \mathrm{~N}_{3} \mathrm{O}_{37}+10 \mathrm{H}_{2} \mathrm{O}: \mathrm{C}: 41.60 ; \mathrm{H}: 6.52 ; \mathrm{N}: 2.75 ; \mathrm{O}: 43.14$; found $\mathrm{C}$ 41.62; H: 5.90; N: 2.30; O: 43.85

\section{Solubility tests in water}

The method reported by Jozwiakowski and Connors was used for the determination of the solubility of all platforms. ${ }^{[38]}$ Appropriate amounts of solid were placed in vials with $1 \mathrm{~mL}$ of $\mathrm{H}_{2} \mathrm{O}$. The samples were stirred in a constant temperature bath at $25.00 \pm 0.01^{\circ} \mathrm{C}$ for $48 \mathrm{hrs}$. The supernatants were then separated from the solid phase at $25^{\circ} \mathrm{C}$ and filtered with Milli-Q membrane filters $(0.45 \mu \mathrm{m}$ pore size) upon injection from $3 \mathrm{~mL}$ disposable plastic syringes and the solutions were analysed for dissolved solid. Supernatant of each sample was placed in at least three different vials. The samples were dried by freeze drying for 2 days and weighted to within $\pm 0.1 \mathrm{mg}$.

\section{Formation of inclusion complexes.}

Inclusion complexes with $\mathrm{AdCOOH}$ were prepared according to the freeze-drying method:[39] $300 \mu \mathrm{L}$ of a $0.185 \mathrm{mmol}^{-\mathrm{L}^{-1}}$ solution of $\mathrm{AdCOOH}$ in $\mathrm{MeOH}$ was added to $3 \mathrm{~mL}$ of an aqueous solution of $\beta-\mathrm{CD}$ compounds $\left(0.0185 \mathrm{mmolL}^{-1}\right.$ in $\mathrm{CD}$ cavity) under vigorous stirring at $40^{\circ} \mathrm{C}$ for $24 \mathrm{~h}$. The resulting solution was freeze-dried to give inclusion complexes.

\section{Job's plot method.}

Two stock solutions, (Sol1) of $\beta-C D$ compound $8 \mathrm{mmol}^{-L^{-1}}$ in $\beta-C D$ cavities, and (Sol2) of AdCOONa ${ }^{[40]} 8 \mathrm{mmol}^{-1}$, were prepared in $\mathrm{D}_{2} \mathrm{O}$. A series of nine samples in NMR tubes containing both $\beta$-CD compound and AdCOONa with a total concentration ([AdCOONa]+[ $\beta-\mathbf{C D}]$ ) fixed at 8 mmol.L-1. This was accomplished by introducing $50 ; 100 ; 150 ; \ldots 450 \mu \mathrm{L}$ of Sol1 in the $1^{\text {st. }} 2^{\text {nd. }} 3^{\text {rd. }} \cdot 9^{\text {th }}$ NMR tube, and then 450 $400 ; 350 ; \ldots ; 50 \mu \mathrm{L}$ of Sol2 in the $11^{\text {st }} ; 2^{\text {nd }} ; 3^{\text {rd }} ; \ldots ; 9^{\text {th }}$ tube. Thus, solutions with constant volume at varying $\beta-C D$ molar fractions $\left(X_{C D}=[\beta-C D] /([\beta-C D]+[\right.$ AdCOONa $\left.])\right)$ in a complete range $(0.1<r<0.9)$ were obtained. The tubes were submitted to NMR analysis, with $\mathrm{D}_{2} \mathrm{O}$ as the internal standard. The continuous variation of the ${ }^{1} \mathrm{H}$ NMR chemicalshift change " $\Delta \delta \times X_{C D}$ " $(\Delta \delta$ taken for the adamantyl H- $\gamma$, see Figure SI38), was plotted against " $\mathrm{XCD}_{\mathrm{CD}}{ }^{[26]}$

\section{Acknowledgements}

We thank Gerardo Cedillo and Miguel Canseco for their assistance in the characterization of the compounds. We are grateful to CONACyT (Projects 253155 and 279380) and PAPIITDGAPA (IN101119) for financial support. I. González-Méndez thanks Posgrado en Ciencias Químicas UNAM and CONACYT for scholarship and financial support, respectively. We are also grateful to the Framework of the French-Mexican International Laboratory (LIA-LCMMC) supported by CNRS and CONACyT, for travel financial support.

\section{Keywords: $\beta$-cyclodextrin • Click Chemistry • PAMAM •} dendrimer $\bullet$ tumbling process

[1] J. Szejtli, Chem. Rev. 1998, 98, 1743-1753.

[2] E.M.M. Del Valle, Process Biochem. 2004, 39, 1033-1046.

[3] a) D.A. Uhlenheuer, K.Petkau, L. Brunsveld, Basic Chem. Soc. Rev. 2010, 39, 2817-2826; b) C. Muankaew, T. Loftsson, Basic Clin. Pharmacol. Toxicol. 2018, 122, 46-55.

[4] a) R. A. Rasheed, C.K.A. Kumar, V.V.N.S.S. Sravanthi, Sci. pharm 2008, 76, 567-598; b) T. Loftsson, M.E. Brewster, J. Pharm. Pharmacol. 2010, 62, 1607-1621; c) B. Gidwani, A. Vyas, Biomed Res. Int. 2015, ID 198268, 15 pages; d) D. Duchêne, A. Bochot, Int. J. Pharm. 2016, 514, 58-72.

[5] a) A. Martinez, C. Ortiz Mellet, J.M. Garcia Fernandez, Chem Soc Rev. 2013, 42, 4746-4773; b) Y. Dinga, V.N.S. Chamakura, V Prasad, C. Ding, B. Wang, Carbohydr. Polym. 2018, 181, 957-963; c) L.J. López-Méndez, I. González-Méndez, R. Aguayo-Ortiz, L. Dominguez, S.L. Alcaraz-Estrada, Y. Rojas-Aguirre, P. Guadarrama, Carbohydr. Polym. 2018, 184, 20-29.

[6] a) J. Li, H. Xiao, J. Li, Y.P. Zhong, Y., Int J Pharm. 2004, 278, 329 342; b) R. W.M. Krause, B.B. Mamba, F.M. Bambo, T. Malefetse in Cyclodextrins: Chemistry and Physics, Chap.9 (Ed.: J. Hu), Transworld Research Network, 2010, 185-210; c) C. Folch-Cano, M. Yazdani-Pedram, C. Olea-Azar, Molecules 2014, 19, 14066-14079.

[7] P. Atul, S. Bhushan, R. Dravyakar, D. Kadam, M. Jadhav, Carbohydr. Polym. 2017, 173, 37-49.

[8] L. Liang, D. Astruc, Coord. Chem. Rev. 2011, 255, 2933-2945.

[9] a) V.K. Tiwari, B.B. Mishra, K.B. Mishra, N. Mishra, S. Anoop, A.S. Singh, X. Chen, Chem. Rev. 2016, 116, 3086-3240; b) P. Thirumurugan, D. Matosiuk, K. Jozwiak, Chem. Rev. 2013, 113, 4905-4979

[10] K. Hattori, H. Ikeda in Cyclodextrins and their complexes, Chap.2 (Ed.: H. Dodziuk), Wiley-VCH, Weinheim, 2006, pp. 31-64.

[11] H. Liu, Y. Zhang, J. Hu, C. Li, S. Liu, Macromol. Chem. Phys. 2009, 210,2125-2137

[12] a) C. Cézard, X. Trivelli, F. Aubry, F. Djedaïni-Pilard, F.Y Dupradeau, Phys. Chem. Chem. Phys. 2011, 13, 15103-15121; b) V. Legros, F. Hamon, B. Violeau, F. Turpin, F. Djedaini-Pilard, J. Désiré, C. Len, Synthesis 2011, 2, 235-242.

[13] a) D. N. Tran, C. Blaszkiewicz, S. Menuel, A. Roucoux, K. Philippot F. Hapiot, E. Monflier, Carbohydr. Res. 2011, 346, 210-218; b) K. Tungala, P. Adhikary, S. Krishnamoorthi, Carbohydr. Polym. 2013, 95, 295-298; c) L. Chen, X. Zhao, Y. Lin, Y. Huanga, Q. Wang, Chem. Commun. 2013, 49, 9678-9680 
[14] a) H. Namazi, A. Heydari, Polym. Int. 2014, 63, 1447-1455; b) Y. Toomari, H. Namazi, Int. J. Polym. Mater. PO 2016, 10, 487-496; c) D.M. Shadrack, H.S. Swai, J.J.E. Munissi, E.B. Mubofu, S.S. Nyandoro, Molecules 2018, 23, 1419-1439.

[15] H. Wang, N. Shao, S. Qiao, Y. Cheng, J. Phys. Chem. B 2012, 116, 11217-11224.

[16] D. Harries, D.C. Rau, V.A. Parsegian, J. Am. Chem. Soc. 2005, 127 2184-2190.

[17] a) D. Granadero, J. Bordello, M.J. Perez-Alvite, M. Novo, W. AlSoufi, Int. J. Mol. Sci. 2010, 11, 173-188; b) L. Wang, L.-I. Li, Y.-s. Fan, H. Wang, Adv. Mater. 2013, 25, 3888-3898; c) J. Sheng, Y. Wang, L. Xiong, Q. Luo, X. Li, Z. Shen, W. Zhu, Polym. Chem. 2017, 8, 1680-1688.

[18] a) M. Mourer, F. Hapiot, E. Monflier, S. Menuel, Tetrahedron 2008, 64, 7159-7163; b) M. Mourer, F. Hapiot, S. Tilloy, E. Monflier, S. Menuel, Eur. J. Org. Chem. 2008, 5723-5730.

[19] Y. Zeng, P. Li, X. Liu, T. Yu, J. Chen, G. Yang, Y. Li, Polym. Chem., 2014, 5, 5978-5984.

[20] H.A. Orgueira, D. Fokas, Y. Isome, P.C.M. Chan, C.M. Baldino, Tet. Lett. 2005, 46, 2911-2914.

[21] V.V. Rostovtsev, L.G. Green, V.V. Fokin, K.B. Sharpless, Angew. Chem. Int. Ed. 2002, 41, 2596-2599.

[22] C. Senac, S. Desgranges, C. Contino-Pépin, W. Urbach, P.F.J. Fuchs, N. Taulier, ACS Omega 2018, 3, 1014-1021.

[23] a) Y. Liu, C.-F. Ke, H.-Y. Zhang, J. Cui, F. Ding, J. Am. Chem. Soc. 2008, 130,600-605; b) K. Yamauchi, A. Miyawaki, Y. Takashima, H. Yamaguchi H., Harada A., Org. Lett. 2010, 12, 1284-1286; c) K. Yamauchi, A. Miyawaki, Y. Takashima, H. Yamaguchi, A. Harada, J. Org. Chem. 2010, 75, 1040-1046; d) Y. Takashima, Y. Fukui, M. Otsubo, N. Hamada, H. Yamaguchi, H.i Yamamoto, A. Harada, Polym. J. 2012, 44, 278-285.

[24] S. Menuel, N. Azaroual, D. Landy, N. Six, F. Hapiot, E. Monflier, Chem. Eur. J. 2011, 17, 3949-3955.

[25] V. Legros, C. Vanhaverbeke, F. Souard, C. Len, J. Désiré, Eur. J. Org. Chem. 2013, 2583-2590.

[26] W. Deng, H. Yamaguchi, Y. Takashima, A. Harada, Chem. Asian J. 2008, 3, 687-695.

[27] N. Six, S.Menuel, H. Bricout, F. Hapiot, E. Monflier, Adv. Synth. Catal. 2010, 352, 1467-1475.

[28] J. Potier, S. Menuel, N. Azaroual, E. Monflier, F. Hapiot, Eur. J. Org. Chem. 2014, 1547-1556.

[29] C.B. Rodell, J.E. Mealy, J.A. Burdick, Bioconjug. Chem. 2015, 26, 2279-2289.

[30] G. Varan, C. Varan, N. Erdogar, A.A. Hincal, E. Bilensoy Int. J. Pharm. 2017, 531, 457-469.

[31] M. Rekharsky, Y. Inoue in Supramolecular Chemistry: From Molecules to Nanomaterials, Vol. 1 (Eds.: P. A. Gale, J. W. Steed), John Wiley \& Sons, Ltd, Chichester, UK, 2012, pp.117-133.

[32] a) H. Arima, F. Kihara, F. Hirayama, K. Uekama, Bioconjugate Chem. 2001, 12, 476-484; b) B.J. Roessler, A.U. Bielinska, K. Janczak, I. Lee, J.R. Jr Baker, Biochem. Biophys. Res. Commun. 2001, 283, 124-129; c) J. Martinelli, K. Thangavel, L. Tei, M. Botta, Chem.: Eur. J. 2014, 20, 10944-10952.

[33] D. Luong, P. Kesharwani, R. Deshmukh, M.C.I. Mohd Amin, U. Gupta, K. Greish, A.K. Iyer, Acta Biomater. 2016, 43, 14-29.

[34] J.-J. Yin, S. Sharma, S.P. Shumyak, Z.-X. Wang, Z.-W. Zhou, Y. Zhang, P. Guo, C.-Z. Li, J. R. Kanwar, T. Yang, S.S. Mohapatra, W. Liu, W. Duan, J.-C. Wang, Q. Li, X. Zhang, J. Tan, L. Jia, J. Liang, M.Q. Wei, X. Li, S.-F. Zhou, PLOS ONE 2013, 8, e62289

[35] E. Folgado, M. Guerre, C. Bijani, V. Ladmiral, A.-M. Caminade, B. Ameduri, A. Ouali, Polym. Chem. 2016, 7, 5625-5629.

[36] S. Rahmani, A.S.Z. Mahani, Macromol. Res. 2015, 23, 1018-1025.

[37] N. Zhong, H.-S. Byun, R. Bittrnan, Tet. Lett. 1998, 39, 2919-2920.

[38] M.J. Jozwiakowski, K.A. Connors, Carbohydr. Res. 1985, 143, 51 59.

[39] a) R. Gharib, H. Greige-Gerges, S. Fourmentin, C. Charcosset, L. Auezova, Carbohydr. Polym. 2015, 129, 175-186; b) J. Sheng, Y. Wang, L. Xiong, Q. Luo, X. Li, Z. Shen, W. Zhu, Polym. Chem. 2017, 8, 1680-1688.

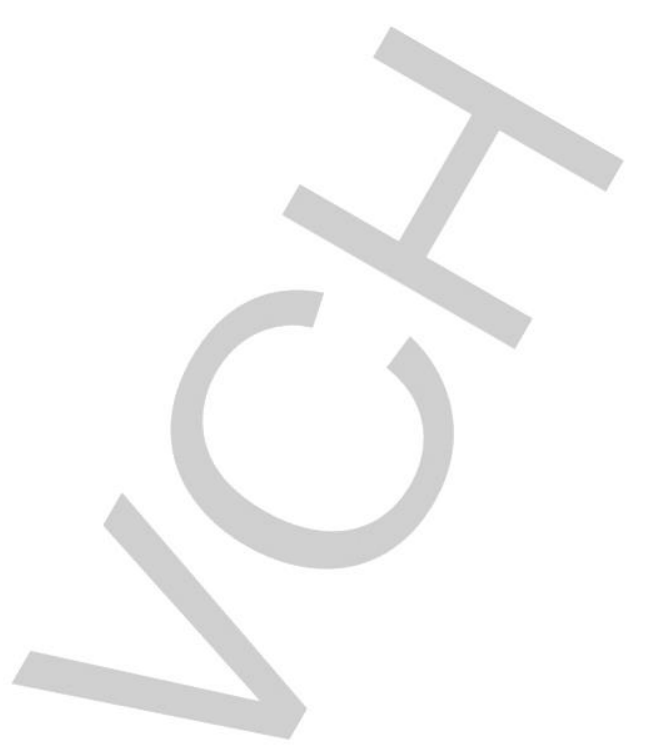




\section{Entry for the Table of Contents}

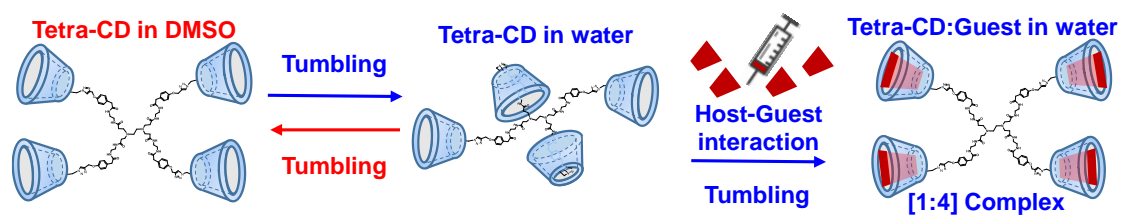

A GO PAMAM dendrimer bearing four $\beta$-cyclodextrin cavities is synthesized through click chemistry. From results of ${ }^{1} \mathrm{H}$ NMR studies and mass spectrometry analyses, we demonstrate that the complexation strength of adamantyl species with cyclodextrin is favourable to the full availability of the cavities in water, despite of a spontaneous tumbling process in that medium for the pristine platform. 